\author{
A. В. Занадворова \\ Институт русского языка им. В. В. Виноградова РАН \\ (Россия, Москва) \\ annazann@gmail.com
}

\title{
ПРОБЛЕМЫ СЛОВАРНОГО ОПИСАНИЯ ГЛАГОЛОВ С ПРИСТАВКАМИ ПОД-, ПРИ- В «ТОЛКОВОМ СЛОВАРЕ РУССКОЙ РАЗГОВОРНОЙ РЕЧИ»
}

Статья посвящена проблеме словарного представления глаголов с приставками под-, nрu- в "Толковом словаре разговорной речи" (ТСРР). Ряд глаголов с этими приставками имеет значение низкой интенсивности действия (например, подвинтить, подработать, подвыпить, подзаправиться и т.п.). В существующих нормативных словарях в толковании этих слов почти всегда присутствует компонент значения 'немного, в небольшом количестве' и/или дополнительности 'в дополнение к имеющемуся'. Ср., например: подбросить (Бросая, добавить; бросить немного); подвинтить (Завинтить добавочно, потуже или немного, слегка); подвыпить (Выпив чего-л. спиртного, слегка опьянеть); приплатить (Заплатить дополнительно, дать в придачу); и др.

Однако указанные компоненты значения проявляют себя не во всех контекстах. В разговорной речи можно встретить немало примеров, когда эти слова сочетаются с наречиями, указывающими на высокую степень/интенсивность действия: хорошенько, как следует, основательно, полностью, изрядно, серьёзно, совсем и т. П.: Теперь мне нужно хорошенечко подзагореть (Блоги, 2015); - Успеем. Как следует подзакусим. Время позволяет (Б. Екимов. Рассказы) и др. Встает вопрос, как отразить в словарной статье такое "нейтральное" употребление, считать ли его отдельным значением. В статье рассматриваются различные способы решения этой проблемы.

Ключевые слова: разговорная речь, кодифицированный литературный язык, лексика, толкование, словарное представление.

В процессе работы над "Толковым словарем русской разговорной речи" авторский коллектив столкнулся с проблемой толкования разговорных глаголов с приставками под-, при- со значением низкой интенсивности действия (например: подзаработать, подзаправиться, подкраситься; приработать, прихворнуть и др.). В словарях в толковании этих слов почти всегда присутствует компонент значения 
'немного, в небольшом количестве' и/или дополнительности 'в дополнение к имеющемуся'. Ср.: толкования из МАС:

подбросить (Бросая, добавить; бросить немного); подварить (Подвергнуть варке еще раз, дополнительно; Сварить или заварить в дополнение к сваренному или заваренному раньше); подвинтить (Завинтить добавочно, потуже или немного, слегка); подвирать (Немного, слегка врать, привирать); подвыпить (Выпив чего-л. спиртного, слегка опьянеть); подгулять (Немного опьянеть, захмелеть); поддразнивать (Слегка, немного подразнить); подзабыть (Частично забыть, не очень твердо сохранить в памяти); подзагореть (Слегка, немного загореть); подзакусить (Немного закусить); подзанять, (Немного занять, взять взаймы); подзаняться (Немного заняться чем-л.); подзаправиться (Немного заправиться); подзапустить (Немного запустить); подзаработать (Немного заработать; дополнительно заработать); подкоротить, (Слегка, немного укоротить); подкрасить$c я$, (Немного, слегка или дополнительно накрасить себе губы, щеки и т. п., окрасить себе волосы); подпортить (Несколько испортить); подправить (Поправить немного, устранив отдельные недостатки, неисправности, ошибки; Восстановить немного здоровье, силы; подлечить); подрезать (Срезая, несколько укоротить, подровнять; Нарезать дополнительно, еще немного); приработать (Заработать немного в дополнение к основному заработку); прихворнуть (Быть больным, болеть, обычно не сильно, не серьезно); приплатить (Заплатить дополнительно, дать в придачу); присолить (Посолить немного или дополнительно).

При реализации таких значений эти глаголы сочетаются обычно с наречиями: чуть-чуть, немного, слегка, капельку и под.: немного подзабыл, слегка подзагорел, чуть укоротил, маленько подзаработал и.т. П. Ср., примеры: Я помню/ это дело в пятом классе проходят// поэтому мы малёк подзабыли// (Из коллекции НКРЯ, 2001); На жаре я там не хочу жариться/ но так вот в хорошую погоду/немножечко хоть подзагореть// (Запись устной речи, 1995); Кажется, никто не против в нерабочее время (а порой и в рабочее) немного подиабашить, подкальмить - и получить дополнительную денюжку (Блоги, 2015).

Однако в разговорной речи фиксируются многочисленные примеры, где эти глаголы сочетаются с наречиями, указывающими на высокую степень/интенсивность действия: хорошенько, вплотную, как следует, основательно, полностью, изрядно, серьёзно, совсем и т. п. С идеей дополнительности подобная сочетаемость не вступает в противоречие, ср.: Колька, пользуясь переездом, крупно подкальмил на тракторе - перевез сруб и пару дней гулял, а сказал, что стоял с пробитой прокладкой (В. Шукшин. Начальник), но, сохраняется ли в таких примерах идея малого количества / слабой интенсивности действия?

Теперь мне нужно хорошенечко подзагореть (Блоги, 2015); - Успеем. Как следует подзакусим. Время позволяет (Б. Екимов. Рассказы); Основательно подзакусив, милищионер Свистулькин снова забрался в постель и решил поспать еще чуточку (Н. Носов. Незнайка в Солнечном городе); Я с четырнадцатого года в окопах/ так что порядком всё подзабыл// (К/ф "Адъютант его превосходительства", 1969); Самой ванной следует основательно подзаняться - тщательно 
вычистить; Ну, знаете, вам придется серьезно подзаняться собой (Блоги, 2017); Советую подзаправиться основательнее (В. Скворцов. Сингапурский квартет); Все просто, покупаем рульки, я взял 3 штуки, перец черный, перец душистый, лавровый лист, зелень и очень крепко присолил; В Китае изрядно подвыпивший мужчина осуществил настоящчй набег на вольер с пандой (Блоги, 2016, 2017).

По-видимому, в подобных примерах глаголы употребляются нейтрально, их значение в таких случаях совпадает со значением глагола без префикса: подзагореть $=$ загореть, подзакусить $=$ закусить, подзаняться = заняться, подзаправиться = заправиться и т. п. Но какую же роль тогда выполняет префикс, что он добавляет? Вероятно, некоторую экспрессию, модальность.

Подобные расхождения употребления со словарными значениями вообще характерны для непринужденного общения, и описаны в ряде монографий по русской разговорной речи. В частности, именно это явление описано в разделе о глагольной префиксации: "Так, глаголы с префиксами под-, прu-, указывающие на небольшую интенсивность действия, используются для выражения вежливости, подчеркнутой симпатии: (о статье): Я бы тебе советовал эту часть подсократить//; (об учебе ребенка) Он у вас немного приотстал//" [РРP 1981: 135].

Как пишет М.В. Панов: "Глагольная приставка под- в обиходной речи служит не столько для обозначения ослабления действия, проявления его не в полную меру, немножко (как говорится в словарных определениях), сколько для выражения разного рода экспрессий (вежливости, иронии, стремления не обидеть и выразить нужную мысль и т. п.)" [РЯСО: 10, цит. по РРР 1981: 135].

Рассмотрим подробнее, какого рода экспрессию могут выражать подобные приставки. Известно, что различные диминутивы часто используются для смягчения высказывания, придания ему большей вежливости, меньшей категоричности. Подобными уменьшительными часто злоупотребляют современные "эффективные менеджеры", в их речи можно встретить слова: договорчик, вопросик, заказик, номерочек, телефончик и т. п. (подробнее об особенностях современного речевого этикета и языке "эффективных менеджеров" см. [Шмелева 2017]).

С идеей уменьшительности коррелирует и идея малого количества/ слабой интенсивности действия, только в глаголах она выражается обычно не с помощью суффиксов, а с помощью приставок. Например: Вам надо хорошенько подучить материал к экзамену// Иначе будет два// (Запись устной речи, 2011); Hу, знаете, вам придется серьезно подзаняться собой (Блоги, 2017). В этих примерах глаголы подучить и подзаняться выражают вежливость по отношению к собеседнику, а наречия хорошенько и серьезно отражают реальное положение дел, т. е. существование у адресата серьезной проблемы.

Также в современной речи часто именно в качестве "вежливых" употребляются слова с приставкой под-: подойти, подъехать, подвезти и т. п. полностью синонимичные однокоренным глаголам с приставкой при-: приехать, привезти и т. п. Ср.: Если удобно/ я к трем часам подъеду/ договорчик подвезу// У вас скидочка будет/ пять процентов//; Подходите к двум часам// Все готово будет// (Записи устной 
речи, 2011, 2015). Впрочем, в данном случае, приставка под- изначально имеет значение не малого количества/слабой интенсивности, а скорее направленности действия.

Также более вежливым считается употребление глагола присесть (вместо сесть): Да вы присядьте/ сейчас он подойдет// (Запись устной речи, 2014). Если вежливое употребление глагола широко распространено, то оно также может получить словарную фиксацию. Например, в ТСРР такие сведения указываются в зоне прагматических сведений о слове. Ср, статью ПРИСЕСТЬ [TCPP 3, 2019].

\section{ПРИСЕ́СТЬ.}

DEF: сесть, обычно на короткое время или не вполне удобно. (На складе:) Да у вас тут и присесть-то некуда// А вот/ на ящик присядьте// (Записи устной речи, 2016); - Позировать, как вы знаете, - это не просто присесть на пару часов и смотреть туда, куда прикажет художник (А. Рыбаков. Тяжелый песок); [Я] присела, но ненадолго, бочком, на табурет... (И. Грекова. Перелом).

MORPH: сов.; несов.(приседать) неупотр.

SYNT: на что или без доп.

PHRAS: присесть некогда - о крайней занятости какою-л. работой. - Девчонки из его лаборатории стонут - присесть некогда... (А. Вайнер, Г. Вайнер. Лекарство против страха); - Днем - работа, семья, присесть некогда, я по ночам смотрю телевизор (Комсомольская правда, 13.04.2007).

PRAGM: в личном общении глагол может употребляться как вежливая форма вместо глагола сесть; ср.: - A паспортистки нету? - Присядьте/ пожалуйста/ щзас я ее позову//; Я щзас освобожусь/ присядьте пожалуйста// (Запись устной речи, 2011, 2016).

Также сочетание глагола с подобной семантикой и слов, обозначающих большое количество, может служить для выражения иронии. Ср., например: Где б нам, мильй, подзанять миллионов 25...; Чтобы выплатить компенсацию помещчикам, Александр II был вынужден в 1862 году подзанять у Ротшильдов 15 миллионов фунтов стерлингов под $5 \%$ годовых; Первоначально Кудрин собирался подзанять в Европе \$17 млрд., но к счастью для Кремля вверх скакнули нефтяные чуень;; Ведь даже большие заправочные корпорации иногда не брезгуют подзаработать миллион-второй долларов за счет низкокачественного бензина; Родители наотрез отказались продавать ее фото прессе, что так принято у голливудских звезд подзаработать миллион-другой на отпрыске (Блоги 2011-2016). Однако любое оценочное слово в принципе может быть употреблено в ироничном контексте, поэтому такие вещи в словаре не фиксируются.

Наконец, подобные глаголы могут употребляться просто нейтральном значении, например, приплатить = заплатить: Любая девочка еще приплатила бы, чтоб получить такую роль (Л. Вертинская. Синяя птица любви); подзагореть = загореть: К кониу я уже так подзагорела/ что меня за местную принимали// 
(Запись устной речи, 2010); подзарядить = зарядить: Даже новый аккумулятор желательно подзарядить, ведь до того, как Вы его купили, он мог пролежать на складе не один месяи (Блоги, 2017).

Возникает вопрос, как описать подобные глаголы в словаре.

Существует несколько вариантов подачи материала. Универсальное решение в данном случае принять невозможно, так как, несмотря на схожесть, указанные глаголы ведут себя по-разному. Одни чаще употребляются в нейтральном значении, другие только иногда и т.п. Важно также анализировать соотношение значений глаголов с приставкой и без, например, глагол подзакусить, образован от глагола закусить, который сам (в одном из своих значений) имеет компонент 'небольшого количества', ср.: "1. Поесть немного, наскоро, или вообще поесть" [MAC].

Укажем основные возможные варианты представления данных слов.

В тех случаях, когда толкование включает два компонента, например: 'поработать немного или в дополнение к основной работе' в каждом конкретном случае в вершине оказывает либо один, либо другой компонент (хотя возможны и оба сразу). Таким образом, примеры с наречиями, выражающими высокую интенсивность действия (сильно, много, хорошенько и т. п.), сочетаются с компонентом толкования 'дополнительно' и не вступают в противоречие с компонентом 'немного'. В этих случаях у глаголов выделяется одно значение. Ср. например, статью ПОДКАЛЫМИТЬ [ТСРР 3, 2019]:

\section{ПОДКАЛЬІМИТь.}

DEF: поработать немного или в дополнение к основной работе. Шестьдесят шесть рублей в месяи, ну и подкалымлю, если кому там вспахать огород или чего (В. Войнович. Монументальная пропаганда); Повезло, что случайный шофер решил подкальмить и повез (С. Лунгин. Виденное наяву); - Ладно, я, - сказал Колька; один раз Колька, пользуясь переездом, крупно подкальмил на тракторе - перевез сруб и пару дней гулял, а сказал, что стоял с пробитой прокладкой (В. Шукшин. Начальник); К тому же неплохо подкальмили, вернемся на шите, то есть со шиитом (Е. Завершнева. Высотка); Где можно подкалымить в воскресенье?; Кажется, никто не против в нерабочее время (а порой и в рабочее) немного подшабашить, подкальмить - и получить дополнительную денюжку (Блоги, 2015-2017).

MORPH: сов.; несов. (подкалымливать) неупотр.

SYNT: где на чем.

SYN: подзаработать, подхалтурить, приработать.

ANALOG: левачить, подрабатывать, халтурить, шабашить, шабашничать.

Если слово часто употребляется в нейтральных контекстах, то можно выделить два значения: 1. Значение, включающее компонент небольшого количества/слабой интенсивности. 2. Нейтральное значение. Ср, например, статью ПРИПЛАТИТЬ [TCPP 3: 2019]. 


\section{ПРИПЛАТИ́ТЬ.}

1. DEF: дополнительно заплатить. Я могу от себя добавить/ если только эти деньги взять/ то этого еще не хватит/ надо будет приплатить// (P/c «Эхо Москвы», 2003); Приплатил чуть-чуть, и билет [на матч] обошелся в четыре с половиной тысячи (Советский спорт, 03.05.2007); Тем, кто согласился бы работать дольше, Зурабов хотел приплачивать $15 \%$ к расчетной пенсии за каждый год дополнительного стажа (Комсомольская правда, 12.10.2011); Стипендия у нас была сто двадцуать, на квартиру приплачивали ещее двадизать пять (А. Найман. Славный конец бесславных поколений).

MORPH: сов.; несов. приплачивать.

SYNT: кому что или сколько (количественно-именная группа).

2. DEF: заплатить. Любая девочка еще приплатила бы, чтоб получить такую роль (Л. Вертинская. Синяя птица любви); «Опель» собирались отволочь на свалку, приплатив тем, кто это сделает (А. Слаповский. Большая Книга Перемен); Всегда найдутся те, кто с радостью пустят ТВ к себе в постель, а может быть, даже сами и приплатят за это - только придите, снимите (Известия, 31.10.2008); Бывает, что автор еще и сам приплачивает за то, чтобы его издали (Комсомольская правда, 13.02.2013); Получается, что ты не просто бесплатно поёшь, но и сам за это ещзе приплачиваешь? (Столица, 18.03.1997).

MORPH: сов.; несов. приплачивать.

SYNT: кому за что.

PRAGM: употребляется в ситуациях, когда обычно предполагается что человек получает за что-л. деньги, а вместо этого он сам их платит.

Можно с помощью слов обычно, как правило, часто в толковании указать, что компонент немного/дополнительно присутствует не всегда. См., например статью ПОДЗАРАБОТАТЬ [ТСРР 3, 2019].

\section{ПОДЗАРАБО́ТАТЬ.}

DEF: обычно заработать немного или в дополнение к основному заработку. $\mathrm{Hy} /$ а пока вот/ не пытались вы куда-нибудь на работу устроиться/ чтоб немножко денег подзаработать/ маме помочь? (Из коллекции НКРЯ, 2006); Мало того что деньжат подзаработали/ они ещё боевой дух нашим ребятам подняли// (Ф. Попов и др. Кавказская рулетка); Сюда приехали в конще июля - «изучать жизнь» и подзаработать на рыборазделке (В. Ремизов. Воля вольная); Играл - нужно было подзаработать, чтобы достроить дачу... (В. Давыдов. Театр моей мечты); Подзаработал немного, а под конец - обогатился даже (А. Иличевский. Бутылка); Занялся изенными бумагами. Хорошо подзаработал. Дом во Флориде купил (С. Данилюк. Рублевая зона); Ее муж подзарабатывал в эти дни на юге большие деньги (В. Маканин. Андеграунд, или герой нашего времени); Наши два сержанта помаленьку подзарабатывали по вечерам на огородах и также были очень довольны (С. М. Голицын. Записки беспогонника). 
MORPH: сов.; несов. подзарабатывать.

SYNT: чего или без доп.

SYN: подхалтурить.

ANALOG: левачить, прирабатывать, шабашить, шабашничать.

Также случаи, где отсутствует компонент 'немного или дополнительно' можно описать в зоне PRAGM (здесь даются прагматические сведения о слове ${ }^{1}$ ). И указать там, что бывают случаи нейтрального или экспрессивного употребления. Ср., например, статью ПОДКРАСИТЬСЯ [ТСРР 3, 2019].

\section{ПОДКРА́СИТЬСЯ.}

DEF: нанести на лицо немного макияжа или слегка обновить старый, а также немного покрасить волосы. - Погоди/ я подкрашусь маленько// - Да ть и так у нас первая красавица/ пошли уже//; (Женщины обсуждаю коллегу:) Я знаю она хной немного подкрашивается// Так/ легкая рыжина получается// (Запись устной речи, 2011); Решила подкраситься. Все равно стояла в пробке; Пришлось за минуту переодеться в машине из шорт и майки в платье с бусами и подкраситься... (Блоги, 2016-1017); Таня цеельй день ждала его звонка. Приготовила праздничный ужин, помыла голову, подкрасилась (М. Трауб. Замочная скважина); - Седина, конечно, вас немного старит, но если подкраситься ... (В. Войнович. Монументальная пропаганда); В его отсутствие я стерла с лица размазанную помаду и подкрасилась (Т. Сахарова. Добрая фея с острыми зубками); Она подкрасилась в лилово-изумрудный оттенок (Л. Петрушевская. Морские помойные рассказы).

MORPH: сов.; несов. подкрашиваться.

SYNT: чем или без доп.

SYN: подмазаться (в 3 знач.), подвести (в 5 знач.).

ANALOG: навести марафет (см. марафет); накраситься, намазаться, намазюкаться (во 2 знач.), намалеваться, намарафетиться, насандалиться (в 1 знач.), наштукатуриться.

PRAGM: часто употребляется в значении 'накраситься, нанести макияж', ср.: Подожди/мне еще в душ нужно и подкраситься/ давай через час выйдем// (Запись устной речи, 2015).

Также, бывают случаи, когда составители считают нужным указать только нейтральное значение. Несмотря на то, что существующих в словарях значение включает компонент небольшого количества / слабой интенсивности. Так как в разговорном узусе эти глаголы преимущественно употребляются нейтрально.

${ }^{1}$ Подробнее о структуре словарной статьи в Толковом словаре русской разговорной речи, см. [TCPP 2014]. 


\section{ПОДЗАПРА́ВИТЬСЯ.}

1. DEF: поесть. Ну и дорожка! Как там насчёт подзаправиться-то? Что на обед сегодня? (К/ф "Алешкина любовь", 1960); Сейчас выедем с территории аэропорта, приткнемся к обочине и вас покормим. Советую подзаправиться основательнее (В. Скворцов. Сингапурский квартет); - Какие у тебя планы? - Сначала, Юр, подзаправиться. В доме ни крошки. (Е. Парнов. Третий глаз Шивы); - Для солдата подзаправиться - первое дело. Голодный солдат не солдат, советую усвоить (А. Чаковский. Блокада); - В гостях сколько ни ешь, а дома подзаправиться не мешает (Н. Носов. Незнайка в Солнечном городе).

MORPH: сов.; несов. нет

SYNT: чем или без доп. .

STYL: шутл.

SYN: заморить червячка (cм. червячок), заправиться, перекусить, перехватить (во 2 знач.), подзакусить, пожевать.

ANALOG: набить пузо (см. пузо), навернуть (в 1 знач.), накушаться (в 1 знач.), налопаться (в 1 знач.), налупиться, напереться ${ }^{2}$, напихаться, нарубаться, слопать, сожрать, стрескать, схомячить, угоститься...

(этот глагол имеет и другие значения, но для данной статьи они не важны)

Также представлен и глагол подзакусить [ТСРР 3, 2019].

\section{ПОДЗАКУСИ́ТЬ.}

DEF: поесть. А мы с тобой побродим... нуу... подзакусим. (К/ф "Первая перчатка", 1956); - Успеем. Как следует подзакусим. Время позволяет (Б. Екимов. Рассказы); Тут я почувствовал, что проголодался, и стал смотреть вокруг себя, где был можно было подзакусить (В. Войнович. Москва 2042); Основательно подзакусив, милиционер Свистулькин снова забрался в постель и решил поспать ещуе чуточку (Н. Носов. Незнайка в Солнечном городе); $A$ теперь я малость подзакушу, а затем продолжу ответ на письма (Ю. Даниэль. Письма из заключения).

MORPH: сов.; несов. нет.

SYNT: чем.

STYL: фам.

SYN: заморить червячка (см. червячок), заправиться, подзаправиться, угоститься.

ANALOG: набить пузо (см. пузо), навернуть (в 1 знач.), накушаться (в 1 знач.), налопаться (в 1 знач.), налупиться, напереться ${ }^{2}$, напихаться, нарубаться, перекусить, слопать, сожрать, стрескать, схомячить.

PRAGM: несмотря на внутреннюю форму (указывающую на неполноту действия), это слово не всегда обозначает небольшую трапезу. Оно сочетается со словами обильно, плотно, основательно: Хоть и плотно подзакусил он у своей хозяйки, но блокада всё ещуе сказывалась: его постоянно тянуло к еде (Ф. Абрамов. Братья и сестры). 


\section{Литература}

Земская Е.А., Китайгородская М.В., Ширяев Е.Н. Русская разговорная речь. Общие вопросы. Словообразование. Синтаксис. М. : Наука, 1981. 276 с.

$M A C$ - Словарь русского языка: В 4 т. / Под ред. А. П. Евгеньевой. 2-е изд., испр. и доп. М. : Русский язык, 1981-1984.

РЯСО - Русский язык и советское общество. Проспект. Алма-Ата, 1962.

ТСРР-1 - Толковый словарь русской разговорной речи. Вып. 1, А - И / Под ред. Л.П. Крысина. М. : Языки славянской культуры, 2014. 776 с.

ТСРР-2 - Толковый словарь русской разговорной речи. Вып. 2, К - О / Под ред. Л.П. Крысина. М. : Языки славянской культуры, 2017. 864 с.

ТСРР-3 - Толковый словарь русской разговорной речи. Вып. 3, П - Р / Под ред. Л. П. Крысина. М. : Языки славянской культуры, 2019. 824 с.

Шмелева Е.Я. Язык "эффективных менеджеров": общий жаргон или русский язык XXI века? // Труды Института русского языка им. В. В. Виноградова. Выпуск 13. Культура русской речи / Отв. ред. выпуска А. Д. Шмелев. М., 2017. сс. 192-198.

\section{A. V. Zanadvorova}

V.V. Vinogradov Russian Language Institute (Russian Academy of Sciences)

(Russia, Moscow)

annazann@gmail.com

\section{PROBLEMS OF LEXICOGRAPHIC DESCRIPTION OF VERBS WITH THE PREFIXES POD-AND PRI- IN THE EXPLANATORY DICTIONARY OF RUSSIAN EVERYDAY SPEECH}

The paper deals with the problem of describing verbs with prefixes pod-and pri- in The Explanatory Dictionary of Russian Everyday Speech (EDRES). These verbs often convey the meaning of low-intensity of action (e.g. podvintit', podrabotat', podvypit', podzapravit'sia, etc.) In the existing conventional dictionaries, descriptions of such verbs include a low-intensity component (e.g. 'a little', 'in a small amount') and/or a complementarity component (e.g. 'additionally'). For example: podbrosit' (add some more, while throwing; throw a little); podvintit' (screw up additionally, tighter; or a little, slightly); podvypit' (after drinking spirits, become a little drunk); priplatit' (pay additionally, give in addition); etc.

However, these semantic components are not clearly manifest in all contexts. In everyday speech there are numerous occurrences of collocations of these verbs with highintensity adverbs: horoshen'ko, kak sleduet (properly), osnovatel'no, polnost'ju (thoroughly), izriadno, ser'jozno (heavily), sovsem (completely), etc.: Teper' mne nuzhno horoshenechko podzagoret' (Now I need to get some sun-tan thoroughly; - taken from a blog); - Uspeem. Kak sleduet podzakusim. Vremja pozvoljaet (We'll make it. We'll grab a bite properly. We have enough time; - from a short story by B. Ekimov). 
Contexts like these pose the question of how such "neutral" uses should be reflected in the EDRES dictionary entries and whether they should be considered distinct meanings. The paper examines several approaches to this problem.

Keywords: everyday speech, codified literary language, vocabulary, interpretation, lexicographic description.

\section{References}

Slovar' russkogo yazyka v 4 t. [The dictionary of the Russian language in 4 vol.]. / Ed. A.P. Evgen'eva. $2^{\text {nd }}$ edition. Moscow : Russian language Publ., 1981-1984 [MAS].

Tolkovyy slovar' russkoy razgovornoi rechi Pod red. L. P. Krysina [The Explanatory Dictionary of Russian Everyday Speech (ed. by L.P. Krysin)], issue 1, Moscow, Yazyki slavyanskoi kul'tury Publ., 2014. 776 p.

Tolkovyy slovar' russkoy razgovornoi rechi Pod red. L. P. Krysina [The Explanatory Dictionary of Russian Everyday Speech (ed. by L.P. Krysin)], the issue 2, Moscow, Yazyki slavyanskoi kul'tury Publ., 2017. 864 p.

Tolkovyy slovar' russkoy razgovornoi rechi Pod red. L. P. Krysina [The Explanatory Dictionary of Russian Everyday Speech (ed. by L.P. Krysin)], the issue 3, Moscow, Yazyki slavyanskoi kul'tury Publ., 2019. 824 p.

Shmeleva E. Ya. [Language of Effective Managers: Common Jargon or Russian of the XXI Century?]. // Trudy Instituta Russkogo Yazyka. Kultura russkoi rechi, vyp. 13 [Proc. of the Vinogradov Russian Language Institute. Russian language culture. Issue 13], 2017, pp. 192-198. (In Russ.)

Zemskaya E.A., Kitaigorodskaya M.V., Shiryaev E.N. Russkaya razgovornaya rech'. Obshchie voprosy. Slovoobrazovanie. Sintaksis [Russian spoken language. General questions. Word formation. Syntax]. Moscow: Nauka Publ., 1981. 276 p. 